\title{
Assessing the dynamics of terms of trade in a model of cumulative causation and structural change
}

\author{
Avaliando a dinâmica dos termos de troca em um modelo \\ de causalidade cumulativa e mudança estrutural
}

RICARDO AZEVEDO ARAUJO*

\begin{abstract}
RESUMO: O objetivo deste trabalho decorre do declínio constante da participação dos gastos de consumo sobre as mercadorias produzidas no Sul globalizado, juntamente com a (empiricamente ambígua) hipótese Singer/Prebisch de que isto pode ser explicado por um declínio secular dos termos do comércio do Sul. Com base nessas pesquisas, o documento propõe estudar a dinâmica dos termos de troca, utilizando um modelo de crescimento multissetorial com base no princípio da causalidade cumulativa. O resultado é um modelo Norte-Sul de crescimento e de comércio em que a evolução dos termos de troca depende de taxas diferenciais de crescimento da produtividade em diferentes setores da economia - e quais os termos de dinâmicas comerciais que podem não ser o melhor caminho no caso de existir ou não m problema de desenvolvimento desigual.
\end{abstract}

PALAVRAS-CHAVE: dinâmica econômica estrutural; termos de troca.

ABSTRACT: The motivation for this paper stems from the steady decline in the share of consumer expenditures on goods produced in the global south, coupled with the (empirically ambiguous) Singer/Prebisch hypothesis that this can be explained by a secular decline in the southern terms of trade. Drawing on these sources of inspiration, the paper sets out to study the dynamics of the terms of trade using a multi-sector growth model based on the principle of cumulative causation. The upshot is a North-South model of growth and trade in which the evolution of the terms of trade depends on differential rates of productivity growth in different sectors of the economy - and in which terms of trade dynamics may not be the best guide as to whether or not there is an uneven development problem.

KEYWORDS: structural economic dynamics; terms of trade.

JEL Classification: O19; F12.

\footnotetext{
* Departamento de Economia, Universidade de Brasilia (UFB), Brasília, DF - Brasil. E-mail: rsaaraujo@ unb.br. Submetido: 23/maio/2014; Aprovado: 10/novembro/2014.
} 


\section{INTRODUCTION $^{1}$}

In discussions of the ever-widening gap between developed and underdeveloped regions, one factor that has received repeated attention is the decline in the share of consumer expenditure on Southern goods. The usual explanation for this phenomenon is Engel's law relating to the difference between the income elasticity of demand for industrial products and that for primary products. Prebisch (1950, $1959,1963)$, for instance, argues that the South typically exports primary products while the North exports industrial products. Engel's law implies a lower income elasticity of demand for primary products. Despite the fact that Engel's law constitutes the most evident abiding causal mechanism blocking rapid growth for poor regions, Prebisch (references above) and Singer (1950) referred to another mechanism that involves a continuous deterioration in the terms of trade. According to these authors the existence of market power in manufacturing sectors and greater degree of organization of workers in industrialized countries may contribute to the declining terms of trade of underdeveloped countries. A country whose terms of trade are worsening loses some of its productivity gains, leaking them to the rest of the world.

This issue that has been investigated by a number of scholars but in fact it is controversial: the great commodity depression of the 1980s and 1990s followed by the boom ${ }^{2}$ in many commodity prices in the 2000s has contributed to raise more doubts about the existence of a specific pattern in the terms of trade. In fact there is a large amount of literature testing the empirical validity of the Singer-Prebisch hypothesis but it is far from being unanimous ${ }^{3}$.

Reinhart and Wickham (1994) for instance have found that the behavior of commodity prices indicates that its weakness is mostly secular, pointing to the need for commodity exporting countries to concentrate on export diversification and other structural policies. They also conclude that the high volatility of commodity prices stresses the importance of precautionary savings and hedging behavior since even temporary shocks tend to persist over several years. Meanwhile, Ram (2004,

\footnotetext{
${ }^{1}$ A preliminary version of this paper was presented at the IX International Colloquium on "Inequality and its Persistence", in Graz, Austria, 2012. The author is grateful to the participants for comments. Financial support from the Brazilian Council of Science and Technology $(\mathrm{CNPq})$ is acknowledged.

2 The boom in the commodity prices may be attributed to two main factors: first the increase in demand exerted by the Chinese economy and second, the process of financialization that assets derived from commodity prices have suffered after the crisis in the world stock market in the 2000s. Ardeni and Wright's (1992) reappraisal of the Prebisch-Singer hypothesis of the deterioration in the terms of trade sheds light on earlier discussions of this matter.

${ }^{3}$ Here the aim is not to provide a thoroughly survey of this literature but only to highlight some
contributions that emphasize two aspects related to this literature that are connected with the aim of
the present paper. First, that a disaggregated approach may yield better results when assessing the
evolution of terms of trade. Second, that there not a final answer to this matter. For a critical review of
the theoretical and empirical literature on the subject and the implications for development strategies
see Ocampo and Parra (2004).
} 
p. 247) by studying the dynamics of terms of trade for a number of countries has concluded that the overall scenario is of sizable negative trends for most developing countries over the thirty-year period 1970 to 1999 . His results rely on the alleged fact that prices of manufactures imported by developing countries from the G5 increased considerably higher than that the prices of manufactures exported by developing countries. Other authors such as Grilli and Yang (1988), Bunzel and Vogelsang (2005) and Zanias (2005) have also found a negative long-run trend in the relative price of primary commodities, confirming the importance of movements in the relative prices of exports of rich and poor nations.

But these results were disputed by Ghoshray (2010) who considers that the use of aggregate measures may yield misleading results since for only a small number of commodities a trend stationary process with a negative trend for the whole period considered were found. For most of the disaggregated price time-series a driftless random walk fits better the data. León and Souto (1997) also considering disaggregated data found that 15 of the 24 commodity prices present negative trends, six are trendless, and three exhibit positive trends. Thus, the Prebisch-Singer hypothesis though not universal, holds for most commodities.

Ocampo and Parra $(2004,2010)^{4}$ have argued that deteriorations in the terms of trade have been discontinuous, with the 1920s and the 1980s being periods for which the decline was particularly notable. One of their main findings is that there were structural breaks in the level of prices that seem to have permanently changed the pattern of time series. Furthermore, these trends have not been uniform across commodity groups. Agricultural products, for example, were responsible for the deterioration in the overall terms of trade of commodities. The group of metal commodities showed relatively constant terms of trade and sharp increases in both times of economic growth of the early twentieth century and early twenty-first century. The view that the decline in commodity prices in the twentieth century was not continuous is also supported by Balagtas and Holt (2006) for whom these events have been episodic.

Mollick et al. (2008) have analyzed if more economic integration amongst countries would eliminate the decline in the terms of trade by comparing the evolution of relative prices within the US, which is considered a highly integrated economy. According to these authors if the US economy could provide support for the Prebish-Singer hypothesis then it would be expected that globalisation would produce the same effect in an integrated world market. Accordingly, this hypothesis was not rejected by them, confirming their initial insight.

If on the empirical front the number of studies on this matter is ubiquitous, on the theoretical side there are relatively few frameworks that tackle this issue. In general, these studies point to differences in determination of prices and wages in industrialized and underdeveloped countries. While the production of primary prod-

\footnotetext{
${ }^{4}$ Their analysis is based on 31 indices of commodity prices for the period between 1865 and 2009. In aggregate form, it is observed is a clear downward trend in commodity prices over the twentieth century.
} 
ucts is usually depicted by perfect competition, manufacturing is characterized by monopolistic competition, mark-up pricing and union-employer bargaining. Sarkar (2001), for instance, develops a neo-Kaleckian framework characterized by surplus capacity, and lack of effective demand in the North and capacity constraint in the South. He shows that the terms of trade would turn against the South even if the North experienced a higher rate of technical progress. Meanwhile, Block and Sapsford (2000) have introduced differences in wage and price determination between primary production and manufacturing to explain the dynamics of terms of trade. Wages and prices in primary production are treated as competitively determined, while in manufacturing they are determined by mark-up pricing and unionemployer bargaining. Although support is found for the Prebisch-Singer hypothesis the authors infer that periods of particularly rapid manufacturing growth are separated by intervals of net improvement in the terms of trade of primary producers.

According to these views, a positive trend in mark-up prices of industrialized goods may be responsible to declining terms of trade for underdeveloped countries. Although dynamics of terms of trade seems to be strongly affected by the dynamic path of mark-up rates, Darity $(1990)^{5}$ disputes this view by showing that this dynamics may be independent of the mark-up rate in industrialized countries. According to him, the degree to which prices exceeds cost in manufacturing would have no effect on the dynamics of the terms trade. A similar result was found by Sarkar (1997): the growth of monopoly power plays no role in explaining the secular deterioration of terms of trade of the South. Considering that the South imports machines from the North, the mechanism behind deterioration of the Southern terms of trade are the productivity improvements through technical progress that lead to a further decline in the Southern terms of trade. Meanwhile, Dutt (1996) also considers a theoretical framework in which the North produces a good used for investment purposes in both the North and the South, and the South produces a good that is used as a primary intermediate good in the North. In his set-up the dynamics of terms of trade rely on the declining demand for Southern primary products in the North due to material-saving technological change. But he concludes that this type of technical change will imply that in the long run the Southern terms of trade will improve rather than deteriorate. Despite the fact that technical progress may lead to the improvement of the Southern terms of trade, it does not mean that it will reverse the widening gap between the two regions.

In the present paper it is built a theoretical approach that intends to tackle the dynamics of terms of trade. While considering different set ups for determination of prices for industrial and underdeveloped countries, another mechanism is taken into account to explain the dynamics of terms of trade, that is cumulative causation. The concept of cumulative causation was systematically developed by Kaldor (1966, 1972) and has been addressed by a number of authors such as Skott (1988),

\footnotetext{
${ }^{5}$ Even in this case, Darity (1990) shows that the Prebisch-Singer result is theoretically possible in the long period in the presence of uniform rates of profit and a mark-up ruling price for the North.
} 
Thirlwall and McCombie (1994), Setterfield (1997) and León-Ledesma (2002) to describe one of the logical effects of what became known in the literature as the Verdoon Law. According to Kaldor the disparities in the growth rates of advanced countries rely on a large extent to the effect of increasing returns to scale in industry, together with a fast growth of this sector. According to this view the growth rate of productivity is strongly determined by the growth rate of output, a view that reverses the direction of the causality posed by the Neoclassical model and gives demand a central role in the process of economic growth. The view that manufacturing plays a special role in terms of backward and forward linkages is related to economies of scale and explains why a faster growth of output led to faster growth of productivity. In this view economic growth is demand induced rather than resource constrained.

Considering that terms of trade vary through time according to changes in productivity in the sectors of specialization, relative to changes in productivity in other sectors, cumulative causation provides the possibility of reversing the continuous deterioration of the Southern terms of trade. This will happen if gains in productivity from cumulative causation are limited to those sectors in which the advanced countries have comparative advantage. A higher rate of technical progress may cause leakage of some productivity gains depending on the structure of the production in each of the countries involved in international intercourse. The composition of exports also plays an important role.

Notwithstanding the strong relation between the patterns of specialization in international trade and economic growth [see Hausmann et al. (2007)] there are few theoretical models showing this result. To the best of my knowledge there is not a single model that studies the dynamics of the terms of trade taking into account cumulative causation. It is somewhat surprising since the rationale of cumulative causation plays an increasing role in the determination of price competitiveness not only in industrial sectors but also in the service sector due to the adoption of Information and Communication Technologies - ICT - through the Verdoorn Law. ICT has been identified as a major determinant of international competitiveness between nations in recent years, through increased labor productivity. And it has also important consequences in terms of the services sector as pointed out by Ocampo et al. (2009). The adoption of ICT is giving rise to the possibility of transferring some services ${ }^{6}$ across countries and what becomes known as the 'dynamic' service export generates high value-added and may play an important role to determine whither the terms of trade.

In this vein, a central point in our analysis is related to the extent to which ICT pervades different sectors of the economy. If ICT is a general purpose technology, we should expect it to be widespread throughout sectors. This view is supported

\footnotetext{
${ }^{6}$ An important issue raised by Ocampo et al. (2009) is whether these service activities can contribute to establishing linkages with other domestic sectors or in the Kaldorian sense of inducing productivity change.
} 
for instance by Jorgenson and Stiroh $(2000$, p. 127) for whom " $[t]$ he diffusion of IT improves business practices, generates spillover benefits, and raises productivity throughout the economy". According to this line of thought, ICT is a fundamental industrial revolution that has a widespread impact over different sectors of the economy. Following this rationaley, we should expect an increasing role for the Kaldor-Verdoorn relation on a sectoral basis. McCombie (2011) for instance considers that cumulative causation plays an important role in the determination of price competitiveness not only in industrial sectors but also in the service sector due to the adoption of Information and Communication Technologies - ICT - through the Verdoorn Law

Considering that terms of trade vary through time according to changes in productivity in the sectors of specialization, relative to changes in productivity in other sectors [see Pasinetti (1981)], cumulative causation provides the possibility of reversing the continuous deterioration of the Southern terms of trade. This will happen if gains in productivity are limited to those sectors in which the advanced countries have comparative advantage.

Here by embedding cumulative causation in the Pasinettian analysis through Kaldor-Verdoorn sectoral laws, technological progress is endogenized for industrial sectors. By following this approach it is also possible to partially endogenize the terms of trade and then perform a theoretical analysis on the possible existence of their deterioration for underdeveloped countries. According to this view a country that has a comparative advantage in industrial sectors may reap stronger benefits of a stronger demand that will be translated in higher rates of productivity. In order to assess the more plausible scenario, that is deterioration or not in the terms of trade, simulations are run by using the theoretical model. The results point to the fact that once a region gains a growth advantage it will tend to sustain that advantage through the process of increasing returns that growth itself induces - the Verdoorn effect. However this phenomenon may have an ambiguous effect in the terms of trade. Another advantage of this approach is that the main channels of interactions between demand, technical progress and structural change are taken into account and in this vein the heterodox view that the process of economic growth in developing countries may be induced by structural changes is confirmed ${ }^{7}$ [see Thirwall (1997)]. Although the current paper is not able to provide a conclusive answer on whiter the terms of trade, apparently it is the extent to which ICT are pervasive throughout the sectors of an economy that determines the final outcome in terms of relative pricees.

This paper is organized as follows: in the next section the approach developed by Araujo (2012) to endogenize technological progress in Pasinetti's model is extended to fully take into account cumulative causation. In the third section, we

\footnotetext{
${ }^{7}$ Of course there is some reciprocity, that is, the technological absorption is determined by the structure of the economy but when technological change is effectively added to the productivity process it affects the structure of the economy.
} 
discuss the determination of the terms of trade following a Pasinettian approach and show some simulation results. Last section closes the paper with the Concluding Remarks.

\section{THE MODEL}

When dealing with free trade and international diffusion of technical progress, Pasinetti $(1981,1993)$ considers a hypothetical case of two countries, one advanced and one underdeveloped, denoted respectively by $\mathrm{A}$ and $\mathrm{U}$, which produce the same set of commodities with different methods of production ${ }^{8}$. According to him the dynamics of the terms of trade depend on changes in productivity in the specialized sectors of the two nations relative to changes in productivity in the other sectors. Whether the terms of trade improve or worsen depends on comparative international changes in productivity and have no relation to the fact that in one country overall productivity may be growing faster or slower than in another. This means, for example, that the faster-growing nation might well be the one which, besides keeping all productivity increases to itself, also absorbs some of the smaller productivity increases achieved by the other countries.

The approach adopted here also follows from Araujo (2012) who extended the Pasinetti model to consider cumulative causation. In Pasinetti's $(1981,1993)$ original model technological progress is exogenous and is particular to each sector. In order to establish the basic notation, it is useful to choose one of the countries, let us say $\mathrm{U}$, to express physical flows. The production coefficients of consumption $a_{n i}$ convey the effect of technological progress in the sector of final goods. Defining productivity in each sector, qi $(t)$ as the inverse of labour coefficient, we have the following identity:

$$
\frac{\dot{q}_{i}}{q_{i}} \equiv \rho_{i} \equiv-\frac{\dot{a}_{n i}(t)}{a_{n i}(t)}
$$

where the rate of technical change for sector $i$ is denoted by $\rho_{i}$. Besides let us consider, following Setterfield (1997, p. 367), that the productivity varies according to a Verdoorn's law. The novelty here is that we assume the Verdoorn law particular to each sector:

$$
\frac{\dot{q}_{i}}{q_{i}}=\gamma_{i}+\alpha_{i} \frac{\dot{X}_{i}(t)}{X_{i}}
$$

Where $\alpha_{i}$ ai is the Verdoorn coefficient. It captures the extent to which output

\footnotetext{
${ }^{8}$ Araujo and Teixeira (2004) formally extended Pasinetti's model to consider international flow of commodities.
} 
growth generates subsequent productivity growth via dynamic increasing returns. Let us assume following Araujo and Lima (2007) that foreign demand is given by the foreign demand coefficient:

$$
a_{i \hat{n}}=\left\{\begin{array}{c}
\left(\frac{p_{i}^{U}}{e p_{i}^{A}}\right)^{\eta_{i}} y_{A}^{\beta_{i}} X_{\hat{n}}^{1-\beta_{i}} \text { if } p_{U}^{i}<e p_{A}^{i} \\
0 \quad \text { if } p_{U}^{i} \geq e p_{A}^{i}
\end{array}\right.
$$

Where $p_{U}^{i}$ and $p_{A}^{i}$ stand for price of the i-th consumption good in countries $\mathrm{U}$ and $\mathrm{A}$, respectively, e stands for the nominal exchange rate, $y_{A}$ is the per capita income of country $A$ and $X_{\hat{n}}$ represents the labour force in country A. $\eta_{i}$ is the price elasticity of demand for export of commodity $i$, with $\eta_{i}<0$, while $\beta_{i}$ is the income elasticity of demand for exports, with $\beta_{i}>0$ is. This specification is according to the Kaldorian view [see Setterfield (2010)] that treats exports as the key source of autonomous demand. First, it allows the larger scale production methods to improve productivity and, second, it encourages the adoption of the best available technologies spurring productivity. By adopting the following convention:

$$
\frac{\dot{p}_{U}^{i}}{p_{U}^{i}}=\sigma_{i}^{U}, \frac{\dot{p}_{A}^{i}}{p_{A}^{i}}=\sigma_{i}^{U}, \frac{\dot{e}}{e}=\varepsilon \frac{y_{A}}{y_{A}}=\sigma_{y}^{A}, \frac{X_{\hat{n}}}{X_{\hat{n}}}=\hat{g}
$$

the growth rate of the foreign demand may be written as:

$$
\frac{\dot{a}_{i \hat{n}}}{a_{i \hat{n}}}=\left\{\begin{array}{cl}
\eta_{i}\left(\sigma_{i}^{U}-\sigma_{i}^{A}-\varepsilon\right)+\beta_{i} \sigma_{y}^{A}+\left(1-\beta_{i}\right) \hat{g} & \text { if } \rho_{i}^{U}<e p_{i}^{A} \\
0 & \text { if } \rho_{i}^{U}<e p_{i}^{A}
\end{array}\right.
$$

Araujo and Teixeira (2003) have shown that in an open version of the Pasinettian model the production of sector $\mathrm{i}$ is given by the internal and foreign demand: $X_{i}=\left(a_{i n}+\xi a_{i n}\right) X_{n}$ In the same vein if the country $\mathrm{U}$ has no comparative cost advantage in producing good $i$ the export per capita demand for commodity $i$ in country $\mathrm{U}$ is equal to zero, that is $a_{i \hat{n}}=0$. Then the growth rate of production of the i-th good in country $\mathrm{U}$ may be written as:

$$
X_{i}= \begin{cases}\theta_{i} \frac{\dot{a}_{i n}}{a_{i n}}+\left(1-\theta_{i}\right) \frac{\dot{a}_{i \hat{n}}}{a_{i n}}+\frac{\dot{X}_{n}}{X_{n}} & \text { if } p_{i}^{U}<e p_{i}^{A} \\ \frac{\dot{a}_{i n}}{a_{i n}}+\frac{\dot{X}_{n}}{X_{n}} & \text { if } p_{i}^{U} \geq e p_{i}^{A}\end{cases}
$$

Where $\theta_{i}$ measures the share of per capita internal demand in total per capita demand for the i-th good. By assuming that internal demand grows exponentially at $r_{i}$ and $\frac{y_{U}}{y_{u}}=\sigma_{y}^{U}$ and by replacing expression (4) into expression (5) we obtain the growth rate of demand for the i-the consumption good as:

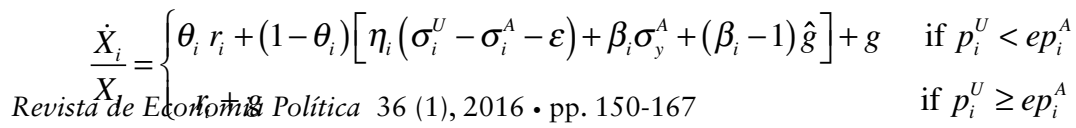


Let us consider that the dynamics of prices are given by the following expressions that entail mark-up rules for the prices both in country $\mathrm{U}$ and $\mathrm{A}$,

$$
\begin{aligned}
& p_{i}^{U}(t)=a_{n i}^{U}(t) w^{U} \\
& p_{i}^{A}(t)=a_{\hat{n} i}^{U}(t) w^{A}
\end{aligned}
$$

Where $w^{U}$ and $w^{A}$ stand for the wages in countries U and A. $a_{\hat{n} \hat{i}}^{A}(t)$ stands for the i-th technical coefficient in the country A. Then, by taking logs and differentiating expressions (7) and (8) we obtain the growth rate of prices in countries $U$ and A are respectively given by $\sigma_{i}^{U}$ and $\sigma_{i}^{A}$ as:

$$
\begin{aligned}
& \sigma_{i}^{U}=\hat{w}_{U}-p_{i}^{U} \\
& \sigma_{i}^{A}=\hat{w}_{A}-p_{i}^{A}
\end{aligned}
$$

Where $\hat{w}_{U}$ and $\hat{w}_{A}$ stand for the growth rates of wages in countries $\mathrm{U}$ and $\mathrm{A}$, respectively, $p_{i}^{U}$ is the rate of technical progress in the i-th sector of $\mathrm{U}$ country and $p_{i}^{A}$ is the rate of technical progress in the i-th sector of A country. Following Araujo (2012) let us also assume that the technical progress in the i-th sector of country A is also given by the Verdoorn law according to:

$$
p_{i}^{A}=\frac{\dot{q}_{i}^{A}}{q_{i}^{A}}=\gamma_{i}^{A}+\alpha_{i}^{A} \frac{\dot{X}_{i}^{A}}{X_{i}^{A}}
$$

Let us consider that the growth rate of the i-th sector in the A country is exogenously given by:

$$
\frac{\dot{X}_{i}^{A}}{X_{i}^{A}}=\lambda_{i}^{A} \sigma_{y}^{A}
$$

Where $\lambda_{i}^{A}$ measures the sensitiveness of the growth rate of demand to the growth rate of per capita income, namely $\lambda_{i}^{A}$. By replacing these expressions (9) and (10) into expression (6) and considering that nominal wage relativities are constant over time we obtain the following growth rate for the production of the i-th sector:

$$
\frac{\dot{X}_{i}}{X_{i}}= \begin{cases}\theta_{i} r_{i}+\left(1-\theta_{i}\right)\left[\eta_{i}\left(\gamma_{i}^{A}+\alpha_{i}^{A} \lambda_{i}^{A} \sigma_{y}^{A}-\rho_{i}-\varepsilon\right)+\beta_{i} \sigma_{y}^{A}+\left(\beta_{i}-1\right) \hat{g}\right]+g & \text { if } p_{i}^{U}<e p_{i}^{A} \\ r_{i}+g & \text { if } p_{i}^{U} \geq e p_{i}^{A}\end{cases}
$$


By inserting expression (11) into expression (2) it is possible to obtain after some algebraic manipulation the rate of technical progress of the $\mathrm{i}$-th sector of $\mathrm{U}$ country:

$$
\rho_{i}= \begin{cases}\frac{\gamma_{i}+\alpha_{i}\left\{\theta_{i} r_{i}+\left(1-\theta_{i}\right)\left[\eta_{i}\left(\gamma_{i}^{A}-\varepsilon\right)+\Omega_{i}^{A} \sigma_{y}^{A}+\left(\beta_{i}-1\right) \hat{g}\right]+g\right\}}{1+\left(1-\theta_{i}\right) \eta_{i} \alpha_{i}} & \text { if } p_{i}^{U}<e p_{i}^{A} \\ \gamma_{i}+\alpha_{i}\left(r_{i}+g\right) & \text { if } p_{i}^{U} \geq e p_{i}^{A}\end{cases}
$$

Where: $\Omega_{i}^{A}=\left(1-\theta_{i}^{U}\right) \eta_{i} \alpha_{i}^{A} \lambda_{i}^{A}+\beta_{i}^{A}$. Since only a continuous devaluation $\varepsilon>0$ will have a positive impact on technical progress and this is implausible let us assume that $\varepsilon=0$. Then we obtain:

$$
\rho_{i}= \begin{cases}\frac{\gamma_{i}+\alpha_{i}\left\{\theta_{i} r_{i}+\left(1-\theta_{i}\right)\left[\eta_{i} \gamma_{i}^{A}+\Omega_{i}^{A} \sigma_{y}^{A}+\left(\beta_{i}-1\right) \hat{g}\right]+g\right\}}{1+\left(1-\theta_{i}\right) \eta_{i} \alpha_{i}} & \text { if } p_{i}^{U}<e p_{i}^{A} \\ \gamma_{i}+\alpha_{i}\left(r_{i}+g\right) & \text { if } p_{i}^{U} \geq e p_{i}^{A}\end{cases}
$$

Note from the expression (13) that technical progress in i-th sector is a function of the growth rate of internal demand and of the elasticity of foreign demand. A country that has access to international trade may enjoy higher rates of technological progress in the sector where it holds comparative advantage. If the growth rate of internal demand is higher than the external demand the country may set $\theta_{i}=0$ and enjoy the higher rate of technological progress. From expression (13) it is also possible to conclude that a country can achieve comparative advantage in some sectors by managing the exchange rate. This allows even greater participation in international trade, which will generate increased productivity due to Verdoorn's law. It is important to consider that this mechanism is of particular importance in industrial sectors where Verdoorn's law is more appropriate to explain the relationship between demand and increases in productivity.

\section{THE DETERMINATION OF THE TERMS OF TRADE}

\section{A Pasinettian Approach}

According to Pasinetti the dynamics of the terms of trade depend on changes in productivity in the specialized sectors of the two nations relative to changes in productivity in the other sectors. Whether the terms of trade improve or worsen depends on comparative international changes in productivity and have no relation to the fact that in one country overall productivity may be growing faster or slower than in another. This means, for example, that the faster-growing nation might well be the one which, besides keeping all productivity increases to itself, also absorbs some of the smaller productivity increases achieved in the other countries.

Let $R_{A}$ and $R_{U}$ be the (weighted) average rates of change of productivity in $A$ 
and in $U$ respectively for those commodities that are produced in both countries (and are mobile, so that they have the same price both in $A$ and in $U$ ), and let $\rho_{A}$ and $\rho_{U}$ be the (weighted) average rates of change of productivity for specialized goods in countries $A$ and $U$, respectively. Then the prices of exports from $A$, relative to the prices of imports from $U$, i.e., the terms of trade, will worsen, improve, or remain unchanged over time according to whether:

$$
\begin{aligned}
& \frac{P_{A}}{R_{A}}>\frac{P_{U}}{R_{U}} \\
& \frac{P_{A}}{R_{A}}<\frac{P_{U}}{R_{U}} \\
& \frac{P_{A}}{R_{A}}=\frac{P_{U}}{R_{U}}
\end{aligned}
$$

Corresponding to each of the above situations, over time, international trade: will cause leakage of some productivity gains from country $A$ to country $U$. will cause leakage of some productivity gains from country $U$ to country $A$. will keep all productivity gains inside the country of origin.

The situation expressed in (ii) is the usual explanation for the secular deterioration in the terms of trade for the South. The traditional argument is that workers in poor regions do not obtain gains in real wages commensurate with growth in their productivity, whilst those in rich regions do. The productivity gains of workers in poor regions are thus passed on to consumers in rich regions via lower prices, whilst workers in rich regions capture productivity increases through growth in real wages, which means that productivity increases in rich regions are not passed on to poor regions in the form of lower prices for the products of the North'.

In order to illustrate the working of the model in the presence of cumulative causation let us fix the ideas by using just three sectors in each country. The weights $a_{1}, a_{2}$, and $a_{3}$ are established according to the participation of each sector in national income of the $U$ country. The rate of change of productivity in each of the sectors is denoted by the following set of rates of technological progress: $\left\{\rho_{1}, \rho_{2}, \rho_{3}\right\}$

Accordingly $R_{U}$ can be written as:

$$
R_{U}=\left\{\rho_{1} a_{1}+\rho_{2} a_{2}+\rho_{3} a_{3}\right\}
$$

where $\sum_{i=1}^{3} a_{i}=1$. Let us assume for the sake of convenience only that country $U$ specializes in producing the consumer good 1 . Hence the average rate of change of productivity for which country $U$ has specialized, $\rho_{U}$, may be written as:

\footnotetext{
${ }^{9}$ According to Dutt (1990, p. 197) "technological change in the North serves to increase the real wage, while in the South it tends to leave Southern workers unaffected, with the benefits passed to Northern workers in the form of a deterioration of the Southern terms of trade".
} 


$$
\rho_{U}=\rho_{1} b_{1}
$$

where $b_{1}$ is the weight associated with the internal and external demand for commodity 1 , with $b_{1}=1^{10}$. Hence:

$$
\rho_{U}=\rho_{1} b_{1}=\rho_{1}
$$

Adopting the same procedure in relation to country $A$ we conclude that the (weighted) average rate of change of productivity in $A$ can be written as:

$$
R_{A}=\rho_{1}^{A} \hat{a}_{1}+\rho_{2}^{A} \hat{a}_{2}+\rho_{3}^{A} \hat{a}_{3}
$$

Country $\mathrm{U}$ has comparative cost advantage in good 1: a raw material that is subject to manufacturing process before reaching final consumers. [Bloch and Sapsford (2000)]

The weights $\hat{\mathrm{a}}_{1}, \hat{\mathrm{a}}_{2}$ and $\hat{\mathrm{a}}_{3}$ are established according to the participation of each sector in national income of country $A$ and $\sum^{3} \hat{a}_{i}=1$. The rate of change of productivity in each of the sectors is denoted by the following set: $\left\{\hat{\rho}_{1}, \hat{\rho}_{2}, \hat{\rho}_{3}\right\}$. Let us consider that country $A$ specializes in producing consumer good 2 . Hence the average rate of productivity change for those commodities for which country $A$ has specialized, $\rho_{A}$, may be written as:

$$
\rho_{A}=\rho_{2}^{A} \hat{b}_{2}
$$

Due to the $\hat{b}_{2}=1$ we can write the above expression as:

$$
\rho_{A}=\rho_{2}^{A} \hat{b}_{2}=\rho_{2}^{A}
$$

The dynamics of the terms of trade, and thus the direction in which productivity may be leaking, depends on ratios of rates of change. For country $U$ this ratio is given by:

$$
\frac{\rho_{U}}{R_{U}}=\frac{\rho_{1}}{\rho_{1} a_{1}+\rho_{2} a_{2}+\rho_{3} a_{3}}
$$

In the case of country $A$ this ratio is given by:

$$
\frac{\rho_{A}}{R_{A}}=\frac{\rho_{2}^{A}}{\rho_{1}^{A} \hat{a}_{1}+\rho_{2}^{A} \hat{a}_{2}+\rho_{3}^{A} \hat{a}_{3}}
$$

\footnotetext{
10 This is a straight consequence of our assumption that the $U$ country exports only good 1 . Then the share in the exports of this good has to be equal to 1 .
} 
Now we are in a position to compare the dynamics of the terms of trade according to the cases expressed by (14), (15) and (16). In the previous section it is shown that that in general a country that has comparative advantage in a specific sector will enjoy higher rates of technological progress in this sector and this may lead to an increase in the technological gap between the sectors of both countries. But from the view of terms of trade, a higher rate of technological progress may lead to deterioration in the terms of trade. This view reinforces Dutt's view $(1996$, p. 87) that "studies connecting the terms of trade deterioration to uneven development may have focused on the wrong issue: those interested in the uneven development process who try to show that the Southern terms of trade deteriorated may be barking up the wrong tree. By the same token, studies denying that this deterioration has occurred have not proved that there has been no uneven development."

Although we can expect a higher rate of technical change in the advanced country, it is not possible to conclude unambiguously that $\frac{\rho_{A}}{R_{A}}>\frac{\rho_{U}}{R_{U}}$, which would mean that international trade causes leakage of some productivity gains from country $A$ to country $U$. In that case, we could expect that the terms of trade would be worsening for the advanced country. And, due to cumulative causation, the terms of trade for the advanced country would be worsening even further, the heavier their concentration of technical improvements in the export industries. In this case the underdeveloped countries would gain since the productivity increases that take place in the exporting sectors of the developed countries would be leaked abroad.

But if, for instance, ICT is a general purpose technology, with its adoption being widespread in the advanced country, then we should expect that an economy that adopts it should be in a better position than an economy in which the generation of technical progress is restricted to the industrial sector. Following this rationale, the adoption of ICT allows the operation of the cumulative causation principle in sectors other than the industrial one, which by its turn produces a better outcome in terms of avoiding that some productivity gains leak abroad. In this case, despite the fact that technical progress entailed by cumulative causation may lead to the improvement of the Southern terms of trade, it does not mean that it will reverse the widening gap between the two regions.

Hence, it is important to take into account that the relation between $\frac{\rho_{A}}{R_{A}}$ and $\frac{\rho_{U}}{R_{U}}$ will also rely on the performance of the exporting sector in the underdeveloped country. If the rate of technical progress in this sector is much higher than in the other sectors, mainly in the industrial one, then the most probable outcome is that $\frac{\rho_{A}}{R_{A}}>\frac{\rho_{U}}{R_{U}}$. That corresponds to the traditional case reported in the literature, which implies deterioration in the underdeveloped country's terms of trade. If it is the case, the effects of cumulative causation cannot reverse the secular downward trend of the Southern terms of trade. Note that the pattern of specialization may also imply this second outcome since technical progress in the industrial sector of the underdeveloped country will not be powered by external demand. 


\section{Numerical Simulations}

In order to illustrate the working of the model it is useful to approach it by using numerical simulations. The aims of these simulations are two-fold. First they show that without any intervention on the exchange rate once a region gains a growth advantage it will tend to sustain that advantage through the process of increasing returns that growth itself induces - the Verdoorn effect. Besides, the simulations show that the most probable outcome is that the country that has a comparative advantage will not face deterioration in its terms of trade. This is somehow surprising since the rationale of technical progress powered by comparative advantage may imply leaks of some of its productivity gains to the other country due to the working of cumulative causation.

The first simulation is based on expression (13). From expressions (7) and (8) the dynamics of prices of the $i$-th good in countries $U$ and $A$ are given by the dynamics of labour coefficients that appear in these expressions. Following Pasinetti (1981), the dynamics of technical coefficients are given by:

$$
\begin{aligned}
& a_{n i}^{U}(t)=a_{n i}^{U}(0) e^{-\rho_{i} t} \\
& a_{\hat{n} i}^{A}(t)=a_{n i}^{A}(0) e^{-\rho_{i}^{A} t}
\end{aligned}
$$

Where $\rho_{i}$ is given by expression (13). The value for $\rho_{i}^{A}$ is also reckoned considering the counterpart of expression (13) for the $A$ country, namely:

$$
\rho_{i}^{A}= \begin{cases}\frac{\gamma_{i}^{A}+\alpha_{i}^{A}\left\{\theta_{i}^{A} r_{i}^{A}+\left(1-\theta_{i}^{A}\right) \eta_{i} \gamma_{i}+\Omega_{i} \sigma_{y}^{U}+\left(\beta_{i}-1\right) \hat{g}+g\right\}}{1+\left(1-\theta_{i}^{A}\right) \eta_{i} \alpha_{i}^{A}} & \text { if } p_{i}^{A}<e^{-1} p_{i}^{U} \\ \gamma_{i}^{A}+\alpha_{i}^{A}\left(r_{i}^{A}+g\right) & \text { if } p_{i}^{A} \geq e^{-1} p_{i}^{U}\end{cases}
$$

Where $\Omega_{i}=\left(1-\theta_{i}^{4}\right) \eta_{i} \alpha_{i} \lambda_{i}+\beta_{i}$

Since the focus of these simulations are on the demand parameters the coefficients of the Verdoorn function are controlled for both regions. They are randomly chosen in each simulation but are the same for both regions. The same happens with other parameters such as populational and income growth. The idea is to isolate the effect of different elasticities of exports and imports for the $i$-th good and variables that are not closely related to it should be controlled. With this approach, it is possible to avoid that comparative advantage departs from one country to other just for technological patterns and shocks. Of course, that this possibility should be taken into account and expression (13) considers this possibility. But our aim here is mainly to analyse the effects of different elasticities on the generation of technological progress.

In order to verify this fact the model developed in second section is run ten 
thousand times over a one hundred period and the mean of these simulations is plotted. The result shows that once a region starts with a growth advantage in a particular sector it will tend to sustain that advantage through the process of increasing returns that growth itself induces - the Verdoorn effect.

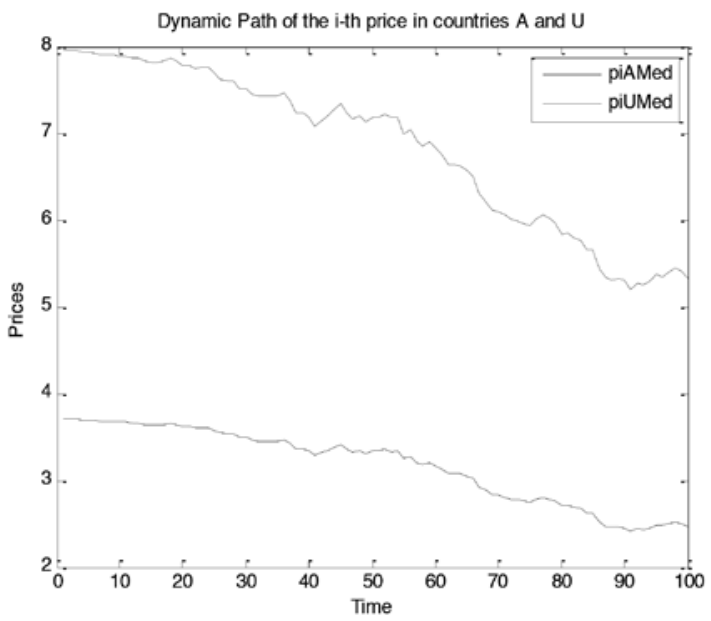

In the second set of simulations, the focus is on the terms of trade expressed by expressions (21) and (22). In this case the set of technical and demand coefficients affect the share of each sector in the national income and the share of exports. As may be seen from the graph below $\frac{\rho_{U}}{R_{\nu}} / \frac{\rho_{A}}{R_{A}}$ is larger than one. Hence we conclude that $\frac{\rho_{U}}{R_{V}}>\frac{\rho_{A}}{R_{A}}$, which means that international trade causes leakage of some productivity gains from country $U$ to country $A$. In this case, the terms of trade are worsening for the underdeveloped country.

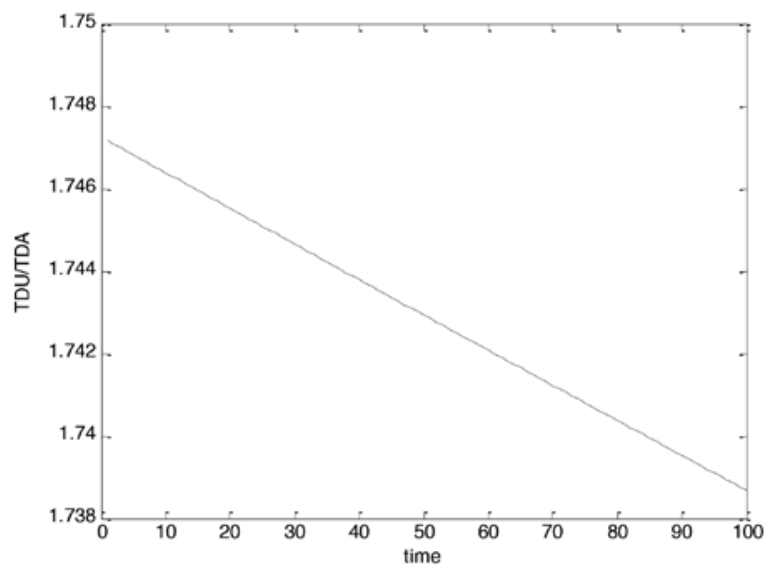

The rationale of cumulative causation implies that once a country obtains comparative advantage it will keep it through time unless external technological 
shocks revert this trend. But the relation between higher rates of technological progress and external demand may prevent the country from retaining the productivity gains and some of them may be leaked to the other country. This may be an explanation of why in some cases the terms of trade seem to be unfavorable to advanced countries. In general these countries have a comparative advantage in industrial sectors, so they can reap the benefits of a higher rate of technological countries due to exports. But a higher rate of technological progress in a particular sector induces a higher competitiveness through a higher rate of decreasing in the domestic price. In the long run this may induce a process of deterioration in the terms of trade for the country that obtains the higher gains in the international intercourse. But the final answer depends on comparisons with the average increase in productivity of the whole economy mainly if there is some channel of diffusion of productivity gains from one sector to others, a possibility that is not considered here. The results obtained here show that cumulative causation does not revert the trend for deterioration in the terms of trade of underdeveloped countries. The rationale for this result may be grasped from the fact that cumulative causation is more pervasive in advanced economies in the sense that the technological improvements brought by the ICT revolution are widespread in all sectors, and not only to the tradable exporting sectors. In this vein, on the theoretical ground it is possible that a country that takes advantage of the returns of scale accruing from cumulative causative in a larger number of sectors may be able to retain some of its productivity gain avoiding deterioration of its terms of trade.

\section{CONCLUDING REMARKS}

Following a structural economic dynamic approach, this paper examines the potential impact of cumulative causation on the dynamics of terms of trade between North-South countries. Cumulative causation although being responsible for generating technical progress may cause leakage of some productivity gains from the exporting sectors to abroad. In this vein possibilities exist that the laggard countries benefit from this effect but the outcome depends on structural economic dynamics of both developed and underdeveloped nations.

According to the approach presented here, the chances of catching up by learning increase with participation in international trade through a mechanism of cumulative causation similar to the 'learning by doing'. This in turn may reinforce the pattern of comparative advantage through increased generation of technical progress, which stems from an increased demand due to the Verdoorn Law. It is shown then that in general a country that has comparative advantage in a specific sector enjoys higher rates of technical progress in this sector and this may lead to an increase in the technological gap with the same sector in the underdeveloped country. But the dynamics of terms of trade depend not only on the sectoral rates of technical progress but also on their relation with the overall productivity of the economy.

The final outcome of our analysis seems to rely on the extent to which cumu- 
lative causation pervades the sectors of advanced and underdeveloped economies. We should expect that it is more pervasive in advanced economies in the sense that the technological improvements brought by the ICT revolution are widespread in all sectors, and not only to the tradable exporting sectors. If, for instance, ICT is a general purpose technology, with its adoption being widespread, then we should expect that an economy that adopts it should be in a better position than an economy in which the generation of technical progress is restricted to the industrial sector. Following this rationale, the adoption of ICT allows the operation of the cumulative causation principle in sectors other than the industrial one, which by its turn produces a better outcome in terms of avoiding that some productivity gains leak abroad. In this vein, a more open economy, which is able to have more access to technical progress, seems to have less chance of experiencing deterioration in its terms of trade, confirming the findings of Mollick et al. (2008).

The framework developed here does not intend to give a definitive answer on this issue but by using some numerical simulations it is possible to grasp some trends that help us to understand the cumbersome movement of terms of trade. Some new efforts should be done in order to endogenize technical progress in primary sectors in which Verdoorn's Law does not provide a good description of the effects of demand on productivity gains. In this vein, it would be possible to provide a better description of the main channels of dependence amongst rich and poor nations.

\section{REFERENCES}

Araujo, R. (2013). "Cumulative causation in a structural economic dynamic approach to economic growth and uneven development”. Structural Change and Economic Dynamics 24, 130 - 140.

Araujo, R. and G. Lima (2007) "A structural economic dynamic approach to balance of payment constrained growth”. Cambridge Journal of Economics 31(5), 755 - 774.

Araujo, R. and J. Teixeira (2003) "An extension of the structural change model to international economic relations". Metroeconomica 54(4), $458-473$.

Ardeni, G. and B. Wright (1992).”The Prebisch-Singer hypothesis: a reappraisal independent of stationarity hypothesis". Economic Journal, 803- 812.

Balagtas, J and M. Holt (2006) "Unit roots, TV-STARs, and the commodity terms of trade: A further assessment of the Prebisch-Singer hypothesis". Selected Paper prepared for presentation at the American Agricultural Economics Association Annual Meeting, Long Beach, CA, July 23-26.

Block, H. and D.Sapsford, D.(2000" "Whither the terms of trade? An elaboration of the Prebisch-Singer hypothesis". Cambridge Journal of Economics, 24, 461 - 481.

Bruton, H. (1998)"A reconsideration of import substitution". Journal of Economic Literature XXXVI, $903-936$.

Bunzel, H. and Vogelsang, T. (2005). "Powerful trend function tests that are robust to strong serial correlation with an application to the Prebisch-Singer hypothesis", Journal of Business and Economic Statistics 23, 381-94

Darity, W. (1990). "The fundamental determinants of the terms of trade reconsidered: long-run and long period equilibrium”. The American Economic Review 80(4), 816 - 827.

Dutt, A. (1990) Growth, Distribution, and Uneven Development. Cambridge: Cambridge University Press. 
Dutt, A. (1996) Southern primary exports, technological change and uneven development”. Cambridge Journal of Economics 20, 73 -89.

Hausmann, R., J. Hwang. and D.Rodrik(2007) “What you export matters". Journal of Economic Growth $12,1-25$.

Jorgenson D. and K.Stiroh (2000) Raising the speed limit: U.S. economic growth in the information Age. Brooking Papers on Economic Activity, I, 125 - 235.

León, J. and Soto, R. (1995). "Structural breaks and long-run trends in commodity prices". Working Paper no. 1406, The World Bank Policy Research.

León-Ledesma, M. (2002) Accumulation, innovation and catching-up: an extended cumulative growth model". Cambridge Journal of Economics 26 (2), $201-216$.

McCombie, J. (2011) "Criticisms and defences of the balance-of-payments constrained growth model: some old, some new”. PSL Quarterly Review 64(259), 353 - 392.

Mollick, A., J. Faria, P. Albuquerque, M. León-Ledesma (2008). "Can globalisation stop the decline in commodities' terms of trade?” Cambridge Journal of Economics 32, $683-701$.

Ocampo, J. and M. Parra (2004). "The commodity terms of trade and their strategic implications for development”. International Trade 0403001, EconWPA.

Ocampo, J. and M. Parra (2010). "The terms of trade for commodities since the mid-19th century. Journal of Iberian and Latin American Economic History 28(1), 11 - 43.

Ocampo, J., C. Rada and L.Taylor (2009). Growth and Policy in Developing Countries: A Structuralist Approach. New York: Columbia University Press.

Pasinetti, L. (1981). Structural Change and Economic Growth - A Theoretical Essay on the Dynamics of the Wealth of the Nations. Cambridge: Cambridge University Press.

Pasinetti, L. (1993) Structural Economic Dynamics - A Theory of the Economic Consequences of Human Learning. Cambridge: Cambridge University Press.

Prebisch, R. (1950). The Economic Development of Latin America and its Principal Problems. New York: ECLA

Prebisch, R. (1959)."Commercial policy in underdeveloped countries”, American Economic Review, Paper and Proceedings, 49(2), $251-73$.

Prebisch, R. (1963). Towards a Dynamic Development Policy for Latin American. New York: United Nations.

Sarkar, P. (1997) "Growth and terms of trade: A North-South macroeconomic framework". Journal of Macroeconomics 19(1), 117 - 133.

Sarkar, P. (2001). "Technical progress and the North-South terms of trade" Review of Development Economics 5(3), p. $433-43$.

Seterfield, M. (1997) "History versus equilibrium' and the theory of economic growth". Cambridge Journal of Economics 21(3), 365-78.

Setterfield, M. (2010). "Endogenous rrowth: A Kaldorian approach". Trinity College Deparment of Economics. Working Paper 10-01.

Singer, H. (1950). "The distribution of gains between investing and borrowing countries". American Economic Review XL, 2, 473 -85.

Ram, R. (2004) “Trends in developing countries' commodity terms-of-trade since 1970” Review of Radical Political Economics 36, 241 - 253.

Reinhart, C. and P. Wickham (1994). “Commodity prices: cyclical weakness or secular decline?” IMF Staff Papers 41, 175-213

Sarkar, P. (1997) "Growth and terms of trade: A north-south macroeconomic framework". Journal of Macroeconomics 19(1), $117-133$.

Thirlwall, A. (1997) "Reflections on the concept of balance-of payments-constrained growth". Journal of Post Keynesian Economics 19(3), 377-86.

Zanias, G. (2005) “Testing for trends in the terms of trade between primary commodities and manufactured goods". Journal of Development Economics 78, 45-59. 